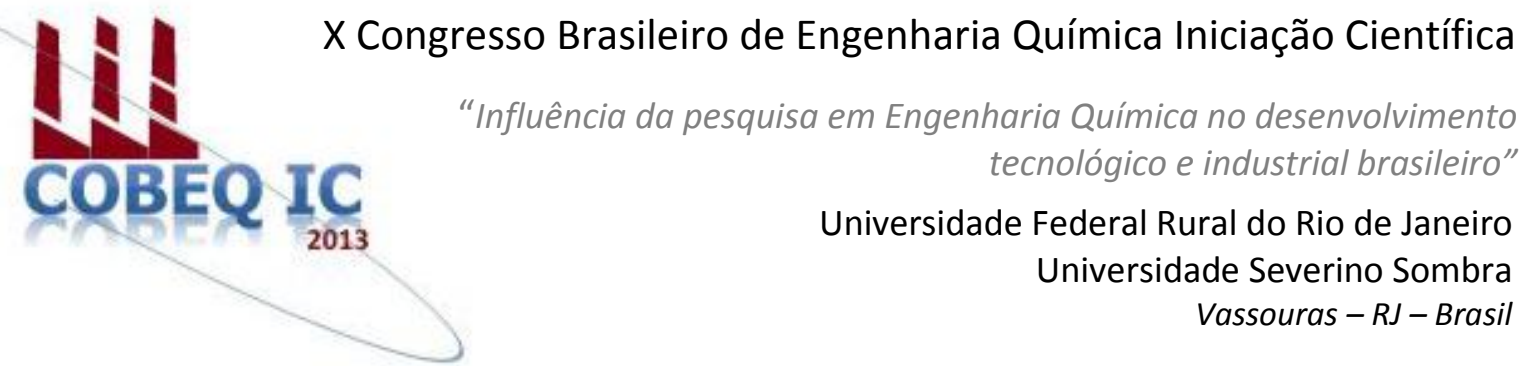

\title{
DETERMINAÇÃO DA EFICIÊNCIA DA EXTRAÇÃO DE ÓLEO DE OURICURI (Syagrus coronata) POR PRENSAGEM HIDRÁULICA
}

\author{
SANTOS $^{* 1}$, B. P. T.; GABRIEL ${ }^{1}$, R.; LIMA ${ }^{1}$, A. K. S.; MOURA ${ }^{2}$, F. B. P.; SOLETTI $^{3}$, J. I.; \\ CARVALHO ${ }^{3}$, S. H. V. \\ ${ }^{1}$ Aluno do CTEC/UFAL $\quad{ }^{2}$ Professor do ICBS/UFAL $\quad{ }^{3}$ Professor do CTEC/UFAL \\ Centro de Tecnologia - Universidade Federal de Alagoas (UFAL) \\ Endereço - UFAL, Av. Lourival Melo Mota, s/n, Cidade Universitária - Maceió - AL, CEP:57072-900 \\ email: jisoletti@gmail.com
}

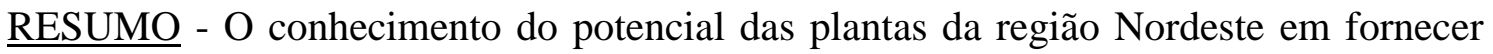
óleo, de uma forma econômica e que valorize plantas nativas, é de suma importância para o desenvolvimento econômico da região cuja agricultura é pouco diversificada. Uma dessas plantas nativas que demonstram grande potencial é a palmeira do ouricuri (Syagrus coronata), originária do sertão baiano, mas presente em boa parte das regiões secas e muito resistente às intempéries do semiárido. Algumas das características importantes dessa oleaginosa é o seu alto teor de óleo de aproximadamente 50\%, o alto aproveitamento artesanal de todas as partes da palmeira e o fato de ser uma grande fonte de $\beta$-caroteno e provitamina A. Com o objetivo promover o desenvolvimento do sertão nordestino foi realizado um estudo sobre os fatores que influenciam a obtenção do óleo bruto do ouricuri. Neste trabalho foi determinado o rendimento da extração do óleo a partir de um planejamento fatorial $2^{2}$ em duplicata, empregando duas variáveis quantitativas (tempo e massa de ouricuri), os níveis utilizados no planejamento foram: 1 e 4 horas, 100 e 400 gramas, respectivamente. Considerando o critério de $95 \%$ de confiança, o tempo não alterou significativamente o processo, sendo a massa a maior responsável por fornecer ganhos à extração.
\end{abstract}

Palavras chave: sertão nordestino, método soxhlet, teor de óleo

\section{INTRODUÇÃO}

O Nordeste brasileiro estava afastado do desenvolvimento científico nacional, mas com o aumento dos investimentos em pesquisa na terceira maior região do país, está sendo possível solucionar muitos problemas, como a grande disparidade social e o baixo conhecimento da flora nordestina. Ouricuri (Syagrus coronata), também chamado de
Licuri é fruto que tem mostrado um grande potencial. Rufino et al. (2008) destacou 32 usos para o ouricuri, divididos em sete categorias: alimento para o homem, alimento de criação, alimento de animais silvestres, construção, artesanato, combustível e medicinal.

Crepaldi et al. (2001) realizaram estudo sobre a composição nutricional do ouricuri, sendo o principal objetivo do trabalho diminuir 
a lacuna existe sobre as espécies do semiárido. $\mathrm{Na}$ amêndoa foi encontrado um teor de proteínas maior que os de outras espécies de palmeiras, mas o teor de $\beta$-caroteno foi inferior as demais espécies semelhantes, mas considerando que em tempos de seca severa, a palmeira do ouricuri tornasse a única fornecedora de alimento. No mesmo estudo foi determinada a quantidade de óleo no ouricuri: polpa $(4,5 \pm 0,3 \%)$ e amêndoa $(49,2 \pm 0,08)$. Considerando que são produzidos combustíveis a partir de espécies com menores teores de óleo, é possível acreditar que o licuri possa ser uma fonte alternativa para produção de biocombustíveis, visto que todas as partes da palmeira podem ser aproveitadas. Mas não basta apenas que o fruto possuía uma boa quantidade de óleo para que seja considerada uma fonte para produção de biocombustíveis, é necessário que se tenha todas as etapas do processo, desde a extração da matéria-prima e obtenção do óleo até a reação de produção de bicombustível, bem desenvolvidas do contrário, o que poderia ser uma solução pode se tornar um grande problema (Leite e Leal, 2007).

Os métodos que podem ser utilizados para obtenção de óleo são: extração mecânica e extração química, esta por sua vez, subdivide-se em extração por solvente e extração por fluido supercrítico. A extração por solvente é uma operação de transferência de massa amplamente utilizada na indústria de alimentos para retirar o óleo de sementes oleaginosas. Estas sementes, após serem preparadas em flocos, são colocadas em um ambiente adequado junto com o solvente de forma a ocorrer transferência do óleo da fase sólida para a fase líquida. Essa operação ocorre seguindo o mecanismo difusional: (1) ocorre o contato do solvente com a superfície do floco; (2) difusão do solvente na superfície do floco até o contato com o óleo; (3) mistura do óleo e o solvente, formando a miscela; (4) drenagem da miscela para um ponto distante do floco (CUSTÓDIO, 2003). O objetivo da extração é que a maior parte de óleo seja extraída com um menor gasto de energia.

Este trabalho visa à determinação do eficiência da extração do óleo de ouricuri via prensa hidráulica, a partir de um planejamento experimental envolvendo 2 fatores, ambos quantitativos: tempo e massa, em dois níveis: 1 e 4 horas, 100 e 400 gramas, respectivamente. Visando à maximização da quantidade de óleo extraída (fator resposta).

\section{METODOLOGIA}

Para a realização da extração mecânica do óleo de ouricuri utilizou-se um planejamento fatorial $2^{2}$ em duplicata, tendo como fatores: tempo de extração e massa da amostra. A Tabela 1 apresenta os níveis para cada um dos fatores estudos no planejamento. $\mathrm{O}$ planejamento fatorial completo $2^{2} \mathrm{em}$ duplicata principia $o$ total de oito experimentos. Optou-se por fixar um valor para a pressão de extração, visto que esse parâmetro possui valores máximos que variam para cada equipamento. A pressão utilizada foi a máxima fornecida pela prensa, Tecnal (TE$098), 15$ ton ( 1 ton equivale a $\left.41,25 \mathrm{kgf} / \mathrm{cm}^{2}\right)$.

Tabela 1 - Planejamento Fatorial $2^{2}$

\begin{tabular}{lcc}
\hline Fator & $\mathbf{- 1}$ & $\mathbf{+ 1}$ \\
\hline Massa (g) & 100 & 400 \\
Tempo (h) & 1 & 4 \\
\hline
\end{tabular}

Os frutos de ouricuri foram colhidos no município de Santana do Ipanema - AL e levados ao Laboratório de Sistemas de Separação e Otimização de Processos (LASSOP/UFAL). Eles possuem epicarpo, mesocarpo e endocarpo bem definidos. Estando a maior quantidade de óleo contida na amêndoa, como apresentado anteriormente. Para se obter as amêndoas em condições de uso, necessitou-se despolpar, e fragmentar o material. Em seguida o produto final foi encaminhado para estufa e permaneceram durante uma semana, sob uma temperatura média de $65^{\circ} \mathrm{C}$.

As massas de cada amostra foram aferidas em balança analítica, antes do início do processo de extração mecânica, sendo o controle da massa de óleo bruto extraído e da massa da torta (material compactado) também realizado. De forma indireta, foi possível obter a massa residual (conteúdo que permanece no equipamento, mesmo após o término do processo, sendo apenas retirado na etapa de limpeza). O óleo foi encaminhado para estocagem e a torta para o pré-condiciona- 
mento, onde foi tratada para o processo de extração por solvente.

A extração química é responsável por retirar o resquício de óleo presente na torta. $\mathrm{O}$ condicionamento consistem em: secagem, de no mínimo 24 horas, moagem (responsável por diminuir a granulometria e favorecer $o$ rendimento da extração) e empacotamento com papel filtro. $O$ método de extração utilizado foi o Soxhlet Padrão a partir do Equipamento B811 (Marca BÜCHI SWITZERLAND, Ano 2011). O tempo de operação foi de 5 horas e o solvente utilizado n-Hexano, determinado a partir de experimento prévio de validação. Essa etapa do experimento também foi realizada em duplicata. A massa de óleo presente no material foi determinada a partir da diferença entre a massa de entrada e a massa de saída.

\section{RESULTADOS E DISCUSSÃO}

A Tabela 2 apresenta os resultados da extração de óleo.

Tabela 2 - Resultados para extração mecânica do óleo de ouricuri

\begin{tabular}{ccccccc}
\hline $\begin{array}{c}\text { Tempo } \\
(\mathbf{h})\end{array}$ & $\begin{array}{c}\text { Massa } \\
(\mathbf{g})\end{array}$ & $\begin{array}{c}\text { Massa torta } \\
(\mathbf{g})\end{array}$ & $\begin{array}{c}\text { Massa óleo } \\
(\mathbf{g})\end{array}$ & $\begin{array}{c}\text { Óleo extraído } \\
(\boldsymbol{\%})\end{array}$ & $\begin{array}{c}\text { Massa residual } \\
(\mathbf{g})\end{array}$ & $\begin{array}{c}\text { Massa residual } \\
(\boldsymbol{\%})\end{array}$ \\
\hline 1 & 100 & 41,8 & 54,3 & 54,45 & 3,9 & 4,50 \\
1 & 100 & 40,2 & 54,6 & & 5,2 & \\
1 & 400 & 168,3 & 227,1 & 55,75 & 4,6 & 1,18 \\
1 & 400 & 176,4 & 218,7 & & 4,9 & \\
4 & 100 & 39,5 & 56,2 & & 4,3 & 4,40 \\
4 & 100 & 39,5 & 56 & 56,10 & 4,5 & \\
4 & 400 & 160 & 237,3 & & 2,7 & 1,16 \\
4 & 400 & 156,9 & 236,5 & 59,22 & 6,6 & \\
\hline
\end{tabular}

Observou-se a partir da Tabela 2, que o resíduo (quantidade que permanece no equipamento após o processo) é proporcionalmente maior quando utiliza-se uma massa menor no processo. Já a porcentagem de óleo extraída, pouco variou, ocorrendo uma maior extração quando o nível superior de tempo (4 horas) foi utilizado. A porcentagem de óleo média extraída foi de $56,38 \%$.

A Tabela 2 também infere que a quantidade de material retida na prensa é em média 4,58 g. Aproveitando-se melhor a extração, quando uma amostra maior é operacionalizada.

As tortas foram encaminhadas para o processo de análise via Sohxlet padrão. A Tabela 3 apresenta os resultados para essa etapa.

A partir da Tabela 3, observou-se que apenas $\mathrm{o}$ experimento com tempo de prensagem de 1 hora e massa de $400 \mathrm{~g}$ apresentou resultados fora do padrão. Também foi possível observar que a extração mecânica não estava sendo operada eficientemente, fornecendo uma torta com mais de $25 \%$ de óleo.

Além disso, observou-se a grande quantidade de sólidos que estavam sendo arrastados. Em estudo ainda não publicado, a média de óleo contida na espécie de ouricuri que foi utilizada nos experimentos é de $51,56 \%$. Conforme apresentado em ambas as tabelas, Tabela 2 e Tabela 3, a porcentagem de óleo final obtida em cada amostra, varia entre $65,5 \%$ e $70,2 \%$, sendo muito maior quando a extração é realizada com $400 \mathrm{~g}$ (Tabela 4).

Apesar de uma quantidade maior de amostra permitir o arraste de material sólido, este fator pode ser corrigido com adições de operações posteriores. Vale ressaltar que o óleo obtido, não está apto ao consumo. Visto isso, a partir dos dados obtidos, a melhor opção para maximizar o rendimento, melhor seria executar uma operação de 4 horas, com 400 g de óleo. 
Tabela 3 - Resultados para análise do material compactado (torta)

\begin{tabular}{ccccc}
\hline Ensaio & $\begin{array}{c}\text { Massa Amostra } \\
(\mathbf{g})\end{array}$ & $\begin{array}{c}\text { Massa Óleo } \\
(\mathbf{g})\end{array}$ & $\begin{array}{c}\text { Teor de Óleo } \\
(\boldsymbol{\%})\end{array}$ & $\begin{array}{c}\text { Média } \\
(\boldsymbol{\%})\end{array}$ \\
\hline & 12,9678 & 3,5585 & 27,4 & \\
Torta & 12,2685 & 3,5513 & 28,9 & 27,1 \\
$(1 \mathrm{~h} / 100 \mathrm{~g})$ & 09,3831 & 2,4811 & 26,4 & \\
& 08,5179 & 2,1923 & 25,7 & 31,4 \\
& 10,0875 & 3,0323 & 30,1 & \\
Torta & 10,0255 & 3,0261 & 30,2 & 27,5 \\
$(1 \mathrm{~h} / 400 \mathrm{~g})$ & 12,0006 & 3,9386 & 32,8 & \\
& 11,8352 & 3,8698 & 32,7 & \\
& 11,4788 & 3,2577 & 28,4 & \\
Torta & 09,7328 & 2,799 & 28,8 & \\
$(4 \mathrm{~h} / 100 \mathrm{~g})$ & 10,2025 & 2,7307 & 26,8 & \\
& 10,0628 & 2,6119 & 26,0 & \\
& 10,2640 & 2,9132 & 28,4 & \\
\hline Torta & 10,8739 & 3,0538 & 28,1 & 27,2 \\
$(4 \mathrm{~h} / 400 \mathrm{~g})$ & 11,8478 & 3,2219 & 27,2 & \\
& 11,1479 & 3,0279 & & \\
\hline
\end{tabular}

Tabela 4 - Teor de óleo final (avaliação do arraste de sólidos)

\begin{tabular}{ccccccc}
\hline $\begin{array}{c}\text { Tempo } \\
(\mathbf{h})\end{array}$ & $\begin{array}{c}\text { Massa } \\
(\mathbf{g})\end{array}$ & $\begin{array}{c}\text { Massa torta } \\
(\mathbf{g})\end{array}$ & $\begin{array}{c}\text { Massa óleo } \\
(\mathbf{g})\end{array}$ & $\begin{array}{c}\text { Massa óleo } \\
(\boldsymbol{\%})\end{array}$ & $\begin{array}{c}\text { Teor de Óleo } \\
\text { na torta }(\%)\end{array}$ & $\begin{array}{c}\text { Teor de oleo } \\
\text { final }(\boldsymbol{\%})\end{array}$ \\
\hline 1 & 100 & 41,8 & 54,3 & 54,45 & 27,1 & 65,58 \\
1 & 100 & 40,2 & 54,6 & & & \\
1 & 400 & 168,3 & 227,1 & 55,75 & 31,4 & 69,27 \\
1 & 400 & 176,4 & 218,7 & & & \\
4 & 100 & 39,5 & 56,2 & 56,10 & 27,5 & 66,95 \\
4 & 100 & 39,5 & 56 & & & \\
4 & 400 & 160 & 237,3 & 59,22 & 27,7 & 70,20 \\
4 & 400 & 156,9 & 236,5 & & & \\
\hline
\end{tabular}

\section{CONCLUSÃO}

O ouricuri é uma espécie em ascensão no Nordeste brasileiro, servindo de alento para o sertanejo durante os períodos de estiagem. Para teores superiores a $40 \%$ de óleo, a extração mecânica é a mais indicada, mas existe a possibilidade de se utilizar em conjunto com a extração por solvente. A quantidade de óleo residual, que permanecia no equipamento até o término da extração, foi praticamente constante, sendo aconselhado que a extração seja realizada com sua carga máxima. Utilizar a maior capacidade de massa, também incrementa a quantidade de sólidos arrastados juntamente com o óleo. Sendo este resultado, amenizado com a adição de operações posteriores a extração. $\mathrm{O}$ aumento do tempo favorece a extração de óleo em até $3 \%$. 


\section{REFERÊNCIAS}

CREPALDI, I. C., ALMEIDA-MURADIAN, L. B., RIOS, M. D. G., PENTEADO, M. V. C., SALATINO, A. Composição nutricional do fruto de licuri (Syagrus coronata (Martius) Beccari). Revista Brasileira de Botânica, São Paulo - SP, V.24, n.2, p. 155-159, 2001.

CUSTÓDIO, A. F. Modelagem e simulação do processo de separação de óleo de sojahexano por evaporação. Campinhas - SP. Unicamp. 2003

LEITE, R. C. DE C.; LEAL, M. R. L. V. O biocombustível no Brasil. Novos estudos, CEBRAP, pp. 15-21, 2007.

RUFINO, M. U. L., COSTA, COSTA, J. T. M., SILVA, V. A., ANDRADE, L. H. C. Conhecimento e uso do ouricuri (Syagrus coronota) e do babaçu (Orbignya phalerata) em Buíque, PE, Brasil. 2008.

\section{AGRADECIMENTOS}

Agradeço ao $\mathrm{CNPq}$, ao Laboratório de Sistemas de Separação e Otimização de Processos (LASSOP), ao Programa Especial de Capacitação Discente (PEC/CTEC/UFAL), e à família. 